\title{
Roux-en-Y Gastric Bypass as an Effective Bariatric Revisional Surgery after Restrictive Procedures
}

\author{
Rosa Marti-Fernandez ${ }^{a} \quad$ Norberto Cassinello-Fernandez ${ }^{a, b}$ \\ Maria Desamparados Cuenca-Ramirez ${ }^{a} \quad$ Maria Lapeña-Rodriguez ${ }^{a}$ \\ Maria Carmen Fernandez-Moreno ${ }^{a}$ Raquel Alfonso-Ballester ${ }^{a}$ \\ Joaquin Ortega-Serrano a, b \\ a Department of General and Digestive Surgery, Hospital Clinico Universitario, Valencia, \\ Spain; ${ }^{b}$ Department of Surgery, University of Valencia, Valencia, Spain
}

\section{Keywords}

Bariatric surgery $\cdot$ Conversion surgery $\cdot$ Gastric bypass $\cdot$ Insufficient weight loss

\begin{abstract}
Introduction: Revisional surgery must be considered when insufficient weight loss is attained or weight is subsequently regained. This study aimed to investigate the value of Roux-en-Y gastric bypass (RYGB) as a revisional procedure after restrictive surgery. Materials and Methods: An observational, retrospective study including patients initially operated on for morbid obesity with restrictive techniques (vertical-banded gastroplasty [VBG], adjustable gastric band $[A G B]$, and sleeve gastrectomy) and reoperated with RYGB in our centre between December 1994 and January 2019. Demographic and anthropometric data, associated comorbidities (diabetes mellitus type II, arterial hypertension, dyslipidaemia, and chronic obstructive pulmonary disease) and surgery-related data (approach, complications, and hospital stay) were evaluated at 5 different time points: initial (prior to first intervention), after the first surgical intervention, before the second intervention (gastric bypass), after the gastric bypass, and at present. Results: A total of 63 patients were included. VBG was the most frequent initial procedure $(n=33)$. The mean age was $39 \pm 9.52$ years, and the average initial weight was
\end{abstract}


$143.53 \pm 28.6 \mathrm{~kg}$. Weight loss was achieved in all groups, with a median excess weight loss of $58 \%$ after the first surgery and $40.3 \%$ after gastric bypass. In terms of weight loss, the best results after the second surgery were obtained when the first surgery was $A G B$, with statistically significant differences. Conclusions: RYGB is effective as a conversion procedure after a previous restrictive surgery, obtaining a significant reduction in weight and BMI. It has an acceptable morbidity rate and is more effective after an AGB.

(C) 2020 The Author(s)

Published by S. Karger AG, Basel

\section{Introduction}

Obesity is a condition with a high prevalence worldwide, with an incidence of $21.6 \%$ in the Spanish population, which positions it as a primary public health problem [1]. Three therapeutic options are used to treat obesity: diet and lifestyle modification, drugs, and surgery. These approaches are not mutually exclusive and, to obtain the best results, they need to be combined in the majority of patients.

Bariatric surgery achieves the best results in terms of weight loss and improvement of comorbidities and produces a reduction in health expenditure [2-5]. Nevertheless, not all the techniques achieve the same results and some studies report that up to $25 \%$ of patients undergoing a restrictive procedure will require a second intervention because of insufficient weight loss [6]. We define bariatric surgery as having failed when $<50 \%$ of excess weight is lost or maintained in the long term, or when, despite having achieved weight loss, the body mass index (BMI) is still $>35 \mathrm{~kg} / \mathrm{m}^{2}[2,7,8]$.

During recent decades, bariatric procedures have moved from restrictive to malabsorptive or combined techniques due to the long-term effects. The goal of this study is to analyse the efficacy, in terms of weight loss and improvement or resolution of comorbidities, of Roux-en-Y gastric bypass (RYGB) as a revisional procedure in obesity after initial restrictive surgery, evaluating if outcomes depend on the first surgery performed.

\section{Materials and Methods}

An observational retrospective study was conducted on patients who had initially undergone open or laparoscopic vertical-banded gastroplasty (VBG), adjustable gastric band (AGB), or sleeve gastrectomy (SG) and were converted to laparoscopic or open RYGB because of either weight regain or insufficient weight loss. The study was conducted at our centre from December 1994 until January 2019 and included a total of 63 patients. Patients who underwent reoperation because of complications related to the first surgery were excluded. All data was anonymized.

We analysed anthropometric data (weight, height, and BMI), associated comorbidities (arterial hypertension, diabetes mellitus type 2 [type 2 DM], chronic obstructive pulmonary disease [COPD], and dyslipidaemia) and surgery-related data (initial surgery type, approach in both surgeries, postoperative complications, and hospital stay) at 5 time points:

1 initial (previous to first surgery)

2 after the first surgery

3 before the second surgery (gastric bypass)

4 after the second surgery (gastric bypass)

5 currently.

A descriptive study of quantitative variables was carried out. They are presented as the mean \pm standard deviation, range, and relative frequency. 
Table 1. Prevalence of comorbidities at the beginning of the study

$\begin{array}{ll}\text { Type 2 DM } & 38.7 \% \\ \text { Arterial hypertension } & 35.5 \% \\ \text { Dyslipidaemia } & 27.4 \% \\ \text { COPD } & 22.6 \%\end{array}$

DM, diabetes mellitus; COPD, chronic obstructive pulmonary disease.

Table 2. Weight and BMI outcomes at different time points

\begin{tabular}{|c|c|c|c|c|c|c|}
\hline & \multicolumn{2}{|l|}{ VBG } & \multicolumn{2}{|l|}{ AGB } & \multicolumn{2}{|l|}{ SG } \\
\hline & weight, kg & BMI, $\mathrm{kg} / \mathrm{m}^{2}$ & weight, kg & BMI, $\mathrm{kg} / \mathrm{m}^{2}$ & weight, kg & BMI, $\mathrm{kg} / \mathrm{m}^{2}$ \\
\hline Initially & $137.62 \pm 19.15$ & $51.37 \pm 7.32$ & $128.37 \pm 16.1$ & $44.38 \pm 6.89$ & $166.72 \pm 25.25$ & $61.73 \pm 8.54$ \\
\hline After first surgery & $94.03 \pm 23.51$ & $35.2 \pm 9.1$ & $100 \pm 6.15$ & $34.98 \pm 5.09$ & $112.11 \pm 18.98$ & $40.75 \pm 7.89$ \\
\hline Before second surgery & $108.56 \pm 21.54$ & $40.45 \pm 7.5$ & $111.87 \pm 22.65$ & $39.02 \pm 6.2$ & $123.22 \pm 2316$ & $45.67 \pm 8.72$ \\
\hline After second surgery & $86.56 \pm 17.85$ & $32.3 \pm 6.59$ & $82.62 \pm 15.13$ & $29.73 \pm 6.39$ & $107.44 \pm 26.94$ & $37.08 \pm 6.55$ \\
\hline Currently & $94.42 \pm 17.81$ & $35.2 \pm 6.95$ & $85.12 \pm 16.58$ & $30.47 \pm 5.78$ & $113.33 \pm 27.64$ & $39.84 \pm 8.65$ \\
\hline
\end{tabular}

Values are expressed as mean \pm SD. VBG, vertical-banded gastroplasty; AGB, adjustable gastric band; SG, sleeve gastrectomy.

The Kolmogorov-Smirnov and Shapiro-Wilk tests were performed to check the normality of data, while Student's $t$ test was conducted for paired samples and to compare continuous variables between the different groups. To assess intergroup differences, ANOVA was used with a Bonferroni post hoc analysis. $p<0.05$ was considered statistically significant.

\section{Results}

Of 63 patients, $69.8 \%(n=44)$ were women. The mean age was $39 \pm 9.52$ years, mean initial weight $143.5 \pm 28.6 \mathrm{~kg}$, and mean initial BMI $53.3 \pm 9.6 \mathrm{~kg} / \mathrm{m}^{2} ; 57.14 \%$ of patients presented with extreme obesity $\left(\mathrm{BMI}>50 \mathrm{~kg} / \mathrm{m}^{2}\right)$. Comorbidities at the start of the study are shown in Table 1.

Thirty-two of the patients were reoperated due to insufficient weight loss, 16 of whom also presented a weight regain. The remaining 31 patients initially had adequate weight loss, but as the follow-up time increased, they presented a progressive regain of weight.

The initial technique was VBG in $52.4 \%$ of cases $(n=33)$, AGB in $19 \%(n=12)$, and SG in $28.6 \%(n=18)$. Table 2 shows weight and BMI changes over time and by primary procedure. Weight loss was observed in all periods, with an average excess weight loss (EWL) of 58\% after the first surgical procedure and $40.3 \%$ after gastric bypass (with respect to the weight before the second intervention).

A decrease in the prevalence of the comorbidities was observed: $38.7 \%$ for type $2 \mathrm{DM}$, $35.5 \%$ for arterial hypertension, $27.4 \%$ for dyslipidaemia, and $22.6 \%$ for COPD prior to the first surgery, which became 25.8, 32.3, 25.8, and 19.4\% after the first intervention, and 16.1, $25,14.3$, and $17.9 \%$ after the second intervention, respectively (Table 3 ). Despite these trends, none of the comorbidities were statistically significant except for type $2 \mathrm{DM}$ after the first surgical intervention and dyslipidaemia after conversion to gastric bypass. In cases in which a comorbidity did not disappear, an improvement was always observed in all cases after the first intervention. 
Table 3. Comorbidity outcomes across different time points

\begin{tabular}{lllll}
\hline & Initially & After 1st surgery & Before 2nd surgery & Currently \\
\hline Type 2 DM & $38.7 \%$ & $25.8 \%$ & $25.4 \%$ & $16.1 \%$ \\
Arterial hypertension & $35.5 \%$ & $32.3 \%$ & $31.7 \%$ & $25 \%$ \\
Dyslipidaemia & $27.4 \%$ & $25.8 \%$ & $25.4 \%$ & $14.3 \%$ \\
COPD & $22.6 \%$ & $19.4 \%$ & $17.5 \%$ & $17.9 \%$ \\
\hline
\end{tabular}

Values denote the percentage of patients affected by the comorbidity. DM, diabetes mellitus; COPD, chronic obstructive pulmonary disease.

Table 4. Occurrence of postoperative complications

\begin{tabular}{lcc}
\hline & First surgery & Second surgery \\
\hline Complications & $10.5 \%$ & $12.3 \%$ \\
Suture leakage & 0 & $1.8 \%$ \\
Wound infection & $5.3 \%$ & $8.9 \%$ \\
Upper gastrointestinal bleeding & $5.3 \%$ & $1.8 \%$ \\
\hline
\end{tabular}

Table 5. Analysis by initial procedure performed (before bypass period vs. current situation)

\begin{tabular}{lllllll}
\hline & VBG & $p$ value & AGB & $p$ value & SG & $p$ value \\
\hline BMI (mean \pm SD) & $-5.2 \pm 6.4$ & $<0.001$ & $-9.9 \pm 7.0$ & $<0.001$ & $-5.2 \pm 7.9$ & 0.035 \\
EWL & $33.7 \%$ & $<0.001$ & $68.5 \%$ & $<0.001$ & $23.6 \%$ & 0.035 \\
\hline
\end{tabular}

BMI, body mass index; EWL, excess weight loss; VBG, vertical-banded gastroplasty; AGB, adjustable gastric band; SG, sleeve gastrectomy.

Regarding the surgical approach, laparoscopy was used for the first operation in 28 patients (45.2\%) and in the second intervention in 29 patients (47.5\%). From 2008 on, all bariatric surgery was carried out by laparoscopy, irrespective of the first surgery or conversion procedure. The mean duration of gastric bypass was $147 \pm 38.66 \mathrm{~min}$. Hospital stay after the second intervention was $5.32 \pm 3.68$ days, which was slightly less than the stay after the first intervention ( $5.82 \pm 2.53$ days). Table 4 shows postoperative major complications after both surgeries, without statistically significant differences between groups.

An improvement in BMI and EWL was observed after every surgical procedure, especially when the initial surgical technique was AGB, with statistically significant differences $(p<0.005)$ (Table 5).

\section{Discussion}

The decision to reoperate on a patient after failed bariatric surgery must be agreed upon by the endocrinologist, nutritionist, and patient, because outcomes in terms of weight loss and improvement of comorbidities are generally variable and the risks of surgery may be higher in a reoperation [9]. 
This type of surgery must be considered in 2 clinical scenarios: when insufficient weight loss is achieved ( $<50 \%$ of excess weight is lost or when the BMI is still $>35 \mathrm{~kg} / \mathrm{m}^{2}$ ) or when weight recidivism appears. The definitive technique must be tailored according to the first surgical procedure performed, the patient's characteristics, and the reason for reoperation. Revisional surgery is a complicated practice due to changes in anatomy since the first surgical intervention and potential adhesions, so it should only be performed in high-volume bariatric units.

When reoperation is needed, physicians must always try to elucidate the reasons the initial surgery failed, although the exact cause is difficult to determine. The necessary complementary preoperative tests are upper gastrointestinal endoscopy and barium swallow studies to evaluate possible anatomic variations since the first bariatric surgery [10-13].

Despite results in terms of weight loss, revisional surgery may be needed because of complications related to restrictive procedures. In the case of AGB, the most frequent complications are band slippage and migration, normally following bad positioning or due to repetitive vomiting, and erosion of the band on the gastric lumen $[10,14,15]$. Characteristic complications related to VBG are the appearance of drug-resistant gastroesophageal reflux (its presence must be ruled out before surgery) and staple line disruption that could produce reservoir dilation and increased intake $[12,16,17]$. Finally, complications that could necessitate revision surgery after VG are gastroesophageal reflux, fistula, and stenotic zones $[18,19]$.

Our study analysed revisional surgery after restrictive techniques following insufficient weight loss or regained weight, excluding complications derived from primary surgery, a scenario that automatically requires reoperation [20,21].

The revisional technique in our study was open or laparoscopic gastric bypass in all cases, since this is considered the best surgical procedure in terms of weight loss and improvement of comorbidities [22, 23], at least after restrictive operations. However, few studies have established the superiority of bypass compared to other bariatric techniques in revisional surgery. Nevo et al. [24] defined it as an effective and safe technique, obtaining $42.6 \%$ excess weight reduction and resolving the comorbidities under study (type $2 \mathrm{DM}$ in $44.4 \%$, arterial hypertension in $45.5 \%$, dyslipidaemia in 50\%, and COPD in 50\% of patients). Brolin and Cody [25], studying 151 cases of revisional surgery in which the first surgical intervention was a restrictive or malabsorptive procedure, concluded that the best outcomes in weight loss and improvement of comorbidities were achieved when the first surgical intervention was a restrictive procedure. They also reported that RYGB is an effective technique with good results, obtaining improvement or resolution of comorbidities in all patients and reducing excess weight by $\geq 50 \%$. Likewise, Carandina et al. [26] reported that laparoscopic gastric bypass obtained better results than sleeve gastrectomy in weight loss and revisional surgery after adjustable gastric band.

If the restrictive surgery was VBG, performing a RYGB could even be considered as a two-step RYGB in patients with extreme obesity, who are the most likely to have a failed VBG. In this sense, the technique of single anastomosis duodenum ileostomy (SADI) is even more appropriate, as it is usually performed with VBG (SADI-S). This kind of reoperation has been published by several authors. Sánchez-Pernaute et al. [27] reported good results and no complications with this procedure but do not recommend it in cases of gastroesophageal reflux disease, inflammatory bowel disease, and cirrhosis. Ceha et al. [28] compared it with RYGB and their results were inconclusive, with similar weight loss and postoperative morbidity; they reported that the surgery took longer, and more defecation problems appeared later. Dijkhorst et al. [29] compared the 2 reoperation techniques in a longer series and reported a similar number of complications and nutritional deficiencies, but that SADI produced better results for weight loss during the first 2 years of follow-up with significant

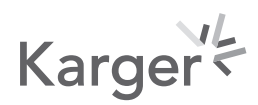


Marti-Fernandez et al.: Gastric Bypass as Revisional Surgery

differences. Both study groups reported a superior initial BMI in patients who underwent SADI $[28,29]$.

There is no indisputable procedure for reoperating patients in whom a restrictive technique has failed, and perhaps the technique should be adapted according to the patient, their BMI, the time elapsed since the first intervention, and the original technique used. For instance, the SADI intervention could be a good option for patients who initially underwent a VBG and presented with a high BMI. In such patients, it is important to take into account their initial BMI before making the decision about the first procedure, which should preferably be a 1- or 2-stage RYGB or SADI-S [30].

In our study, all patients had significant weight loss, irrespective of the first surgical procedure. Comparing weight loss by the initial procedure revealed that the best results were obtained when the first procedure was AGB reaching a BMI of $30.47 \pm 5.65 \mathrm{~kg} / \mathrm{m}^{2}$, followed by VBG reaching $35.2 \pm 6.89 \mathrm{~kg} / \mathrm{m}^{2}$, and finally SG which reached a BMI of $39.84 \pm 8.28 \mathrm{~kg} /$ $\mathrm{m}^{2}$. Despite these successful weight loss outcomes, the same results were not obtained with controlling comorbidities; we achieved a statistically significant improvement only in dyslipidaemia after gastric bypass. In most cases, an improvement in comorbidities was observed after the first operation and lasted over time. An interesting finding is that the complication rate and hospital stay were very similar between the first and second surgery, without serious adverse events after the second intervention.

In cases of a failed bariatric procedure (especially after AGB), reintervention is usually beneficial; however, in our opinion, the most important finding of this work is that the longterm outcomes due to insufficient weight loss or weight regain after revisional surgery were usually similar to the initial loss after the first surgery, although it is true that the trend to continue gaining weight was usually stopped. This should be explained to patients before undergoing the second surgery, also taking into account the surgical risks.

The best results were obtained after AGB, probably because these patients had a poor excess weight loss after the first intervention (Table 2). RYGB has been shown to be a good revisional technique in addition to a safe procedure with a low rate of postoperative complications (1.8\% leakage) and no mortality, making it advisable to be performed in a highvolume bariatric unit. Similar results were found by other studies, where the morbidity rate was slightly higher after revisional surgery and there was no mortality [24, 31].

Some limitations of our work are the retrospective character of the study, the small sample size, and differences across groups in initial BMI (clearly lower in the AGB group). This may also explain the better result of the reoperation in these cases, since the amount of weight lost after a RYGB is usually lower in extreme obesity.

\section{Conclusion}

RYGB is a safe and effective technique for revisional bariatric surgery after a previous restrictive technique, attaining a significant but limited reduction in weight and BMI and an acceptable morbidity rate. The results of RYGB as a revisional technique are better when AGB was the first intervention.

\section{Acknowledgements}

We acknowledge the help of the student Carlos Fairen-Oro in data collection.

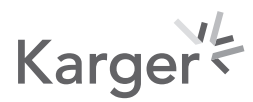


Marti-Fernandez et al.: Gastric Bypass as Revisional Surgery

\section{Statement of Ethics}

This research complies with the guidelines for human studies. This study was approved by the Ethics Committee for Research of the University Clinical Hospital of Valencia, which considered that informed consent was not necessary due to the characteristics of the study.

\section{Disclosure Statement}

The authors declare no conflicts of interest.

\section{Funding Sources}

There was no funding.

\section{Author Contributions}

Conception and design of the work: N.C.-F., R.A.-B., and J.O.-S.; data collection: R.M.-F., M.D.C.-R., and J.O.-S.; drafting the article: R.M.-F., N.C.-F., and J.O.-S.; critical revision of the article: N.C.-F. and J.O.-S. Data analysis and interpretation and final approval of the version to be published were conducted by all authors.

\section{References}

1 Aranceta-Bartrina J, Pérez-Rodrigo C, Alberdi-Aresti G, Ramos-Carrera N, Lázaro-Masedo S. Prevalencia de obesidad general y abdominal en la población adulta Española (25-64 años) 2014-2015: Estudio ENPE. Rev Esp Cardiol. 2016;69:579-87.

2 Colquitt JL, Pickett K, Loveman E, Frampton GK. Surgery for weight loss in adults. Cochrane Database Syst Rev. 2014 Aug; 8:CD003641.

3 Díez I, Martínez C, Sánchez-Santos R, Ruiz JC, Frutos MD, De la Cruz F, et al. Recomendaciones de la SECO para la práctica de la cirugía bariátrica y metabólica (Declaración de Vitoria-Gasteiz, 2015). BMI. 2015;5.3.3:842-5.

4 Bond DS, Phelan S, Leahey TM, Hill JO, Wing RR. Weight-loss maintenance in successful weight losers: surgical vs non-surgical methods. Int J Obes. 2009 Jan;33(1):173-80.

5 Christou NV, Sampalis JS, Liberman M, Look D, Auger S, McLean AP, et al. Surgery decreases long-term mortality, morbidity, and health care use in morbidly obese patients. Ann Surg. 2004 Sep;240(3):416-23.

6 Mor A, Keenan E, Portenier D, Torquati A. Case-matched analysis comparing outcomes of revisional versus primary laparoscopic Roux-en-Y gastric bypass. Surg Endosc. 2013 Feb;27(2):548-52.

7 Patel S, Szomstein S, Rosenthal RJ. Reasons and outcomes of reoperative bariatric surgery for failed and complicated procedures (excluding adjustable gastric banding). Obes Surg. 2011 Aug;21(8):1209-19.

8 Maleckas A, Gudaitytė R, Petereit R, Venclauskas L, Veličkienè D. Weight regain after gastric bypass: etiology and treatment options. Gland Surg. 2016 Dec;5(6):617-24.

9 Aarts E, Koehestanie P, Dogan K, Berends F, Janssen I. Revisional surgery after failed gastric banding: results of one-stage conversion to RYGB in 195 patients. Surg Obes Relat Dis. 2014 Nov-Dec;10(6):1077-83.

10 Coblijn UK, Verveld CJ, van Wagensveld BA, Lagarde SM. Laparoscopic Roux-en-Y gastric bypass or laparoscopic sleeve gastrectomy as revisional procedure after adjustable gastric band-a systematic review. Obes Surg. 2013 Nov;23(11):1899-914.

11 Noel P, Schneck AS, Nedelcu M, Lee JW, Gugenheim J, Gagner M, et al. Laparoscopic sleeve gastrectomy as a revisional procedure for failed gastric banding: lessons from 300 consecutive cases. Surg Obes Relat Dis. 2014 Nov-Dec;10(6):1116-22.

12 Chowbey PK, Soni V, Kantharia NS, Khullar R, Sharma A, Baijal M. Laparoscopic Roux-en-Y gastric bypass: outcomes of a case-matched comparison of primary versus revisional surgery. J Minim Access Surg. 2018 Jan-Mar; 14(1):52-7.

13 Zhang L, Tan WH, Chang R, Eagon JC. Perioperative risk and complications of revisional bariatric surgery compared to primary Roux-en-Y gastric bypass. Surg Endosc. 2015 Jun;29(6):1316-20.

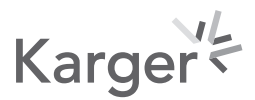


14 Victorzon M, Tolonen P. Mean fourteen-year, 100\% follow-up of laparoscopic adjustable gastric banding for morbid obesity. Surg Obes Relat Dis. 2013 Sep-Oct;9(5):753-7.

15 O’Brien PE, MacDonald L, Anderson M, Brennan L, Brown WA. Long-term outcomes after bariatric surgery: fifteen-year follow-up of adjustable gastric banding and a systematic review of the bariatric surgical literature. Ann Surg. 2013 Jan;257(1):87-94.

16 Bolton J, Gill RS, Al-Jahdali A, Byrns S, Shi X, Birch DW, et al. Endoscopic revision (StomaphyX) versus formal surgical revision (gastric bypass) for failed vertical band gastroplasty. J Obes. 2013;2013:108507.

17 Hedberg J, Gustavsson S, Sundbom M. Long-term follow-up in patients undergoing open gastric bypass as a revisional operation for previous failed restrictive procedures. Surg Obes Relat Dis. 2012 Nov-Dec;8(6):696701.

18 Sugerman HJ, Kellum JM Jr, DeMaria EJ, Reines HD. Conversion of failed or complicated vertical banded gastroplasty to gastric bypass in morbid obesity. Am J Surg. 1996 Feb;171(2):263-9.

19 Biter LU, Gadiot RP, Grotenhuis BA, Dunkelgrün M, van Mil SR, Zengerink HJ, et al. The Sleeve Bypass Trial: a multicentre randomized controlled trial comparing the long-term outcome of laparoscopic sleeve gastrectomy and gastric bypass for morbid obesity in terms of excess BMI loss percentage and quality of life. BMC Obes. 2015 Aug;2(1):30.

20 Dapri G, Cadière GB, Himpens J. Laparoscopic conversion of adjustable gastric banding and vertical banded gastroplasty to duodenal switch. Surg Obes Relat Dis. 2009 Nov-Dec;5(6):678-83.

21 Elazary R, Hazzan D, Appelbaum L, Rivkind AI, Keidar A. Feasibility of sleeve gastrectomy as a revision operation for failed silastic ring vertical gastroplasty. Obes Surg. 2009 May;19(5):645-9.

22 Adams TD, Davidson LE, Litwin SE, Kim J, Kolotkin RL, Nanjee MN, et al. Weight and Metabolic Outcomes 12 Years after Gastric Bypass. N Engl J Med. 2017 Sep;377(12):1143-55.

23 Fruh SM. Obesity: risk factors, complications, and strategies for sustainable long-term weight management. J Am Assoc Nurse Pract. 2017 Oct;29 S1:S3-14.

24 Nevo N, Abu-Abeid S, Lahat G, Klausner J, Eldar SM. Converting a Sleeve Gastrectomy to a Gastric Bypass for Weight Loss Failure-Is It Worth It? Obes Surg. 2018 Feb;28(2):364-8.

25 Brolin RE, Cody RP. Weight loss outcome of revisional bariatric operations varies according to the primary procedure. Ann Surg. 2008 Aug;248(2):227-32.

26 Carandina S, Maldonado PS, Tabbara M, Valenti A, Rivkine E, Polliand C, et al. Two-step conversion surgery after failed laparoscopic adjustable gastric banding. Comparison between laparoscopic Roux-en-Y gastric bypass and laparoscopic gastric sleeve. Surg Obes Relat Dis. 2014 Nov-Dec;10(6):1085-91.

27 Sánchez-Pernaute A, Rubio MA, Conde M, Arrue E, Pérez-Aguirre E, Torres A. Single-anastomosis duodenoileal bypass as a second step after sleeve gastrectomy. Surg Obes Relat Dis. 2015 Mar-Apr;11(2):351-5.

28 Ceha CM, van Wezenbeek MR, Versteegden DP, Smulders JF, Nienhuijs SW. Matched Short-Term Results of SADI versus GBP after Sleeve Gastrectomy. Obes Surg. 2018 Dec;28(12):3809-14.

29 Dijkhorst PJ, Boerboom AB, Janssen IM, Swank DJ, Wiezer RM, Hazebroek EJ, et al. Failed Sleeve Gastrectomy: Single Anastomosis Duodenoileal Bypass or Roux-en-Y Gastric Bypass? A Multicenter Cohort Study. Obes Surg. 2018 Dec;28(12):3834-42.

30 Díaz-Tobarra M, Cassinello Fernández N, Jordá Gómez P, Nofal MN, Alfonso Ballester R, Ortega Serrano J. OneStage vs. Two-Stage laparoscopic Roux-en-Y Gastric Bypass in obese patients with Body Mass Index $55 \mathrm{~kg} /$ m2; five-year follow-up. Obes Surg. 2017 Apr;27(4):955-60.

31 Sharples AJ, Charalampakis V, Daskalakis M, Tahrani AA, Singhal R. Systematic Review and Meta-Analysis of Outcomes after Revisional Bariatric Surgery following a Failed Adjustable Gastric Band. Obes Surg. 2017 Oct; 27(10):2522-36. 